\title{
Essais
}

ESSAIS

Revue interdisciplinaire d'Humanités

12 | 2017

Textes et contextes : entre autonomie et dépendance

\section{Intersubjectivity in media consumption as a result of the relation between text and context: the case of Game of Thrones}

Carlo Galimberti and Carmen Spanò

\section{(2) OpenEdition \\ Journals}

Electronic version

URL: http://journals.openedition.org/essais/3091

DOI: 10.4000/essais.3091

ISSN: 2276-0970

Publisher

École doctorale Montaigne Humanités

Printed version

Date of publication: 15 June 2017

Number of pages: 191-208

ISBN: 979-10-97024-02-4

ISSN: $2417-4211$

Electronic reference

Carlo Galimberti and Carmen Spanò, «Intersubjectivity in media consumption as a result of the relation between text and context: the case of Game of Thrones », Essais [Online], 12 | 2017, Online since 12 October 2020, connection on 25 October 2020. URL : http://journals.openedition.org/essais/ 3091 ; DOI : https://doi.org/10.4000/essais.3091 


\title{
Intersubjectivity in media consump- tion as a result of the relation between text and context: the case of Game of Thrones
}

\author{
Carlo Galimberti, Carmen Spanò
}

"Where was the link, the swaying rope-bridge, between that then and this now?"

\section{Introduction}

The current media landscape is in a state of notable transition. The convergence of media forms, described as "the flow of content across different media platforms, the migration of audiences and co-operation between different media industries" ${ }^{2}$, has generated a framework of intertwined technological and cultural practices. The notion of convergence culture ${ }^{3}$ helps to explain how these transformations, on both the technological side (multiplication of media platforms, digitalization of media contents) and the narrative side (transmedia storytelling), give rise to a new context in which media contents are distributed and consumed. Media are disseminated through a range of alternative platforms -generally smaller and portable, like laptops, smartphones and/or tablets, thus easier to relate to- and within a constellation of offers of additional content that has molded television stories out of expanded, branded universes. In this regard, the diffusion of trans-media storytelling as a strategy used by media conglomerates has provided the original cores of television programs like TV series with multiple entry points through which consumers can immerse into their imaginary worlds. As Henry Jenkins asserts: "A trans-media story unfolds across multiple media platforms with each new text making a distinctive and valuable contribution to the whole. In the ideal form of trans-media storytelling, each medium does what it does best -so that a

\footnotetext{
1 Benjamin Black (aka John Banville), The Lemur, London, Pan Macmillan Ltd, 2008, p. 33.

2 Mark Duffett, Understanding fandom: An introduction to the study of media fan culture, Bloomsbury Publishing USA, 2013. This is the core argument discussed by Duffett in "How has the internet shaped fan cultures?", a fundamental paragraph of the chapter 9 of his work.

3 Henry Jenkins, Convergence Culture: Where Old and New Media Collide, New York-London, NYU Press, 2006.
} 
story might be introduced in a film, expanded through television, novels, and comics; its world might be explored through game play or experienced as an amusement park attraction ${ }^{4}$.

Audience members smoothly move from one platform to the other, are capable of processing various media texts at the same time and refer to different spatial contexts while they are performing these multiple tasks.

TV shows like Game of Thrones (HBO) help to properly understand and explore the idea of trans-media storytelling with reference both to the transformations in the contemporary fictional narratives and to the audiences' consumption habits. They are indeed "complex textual networks", forms of "entertainment for the age of media convergence, integrating multiple texts to create a narrative so large that it cannot be contained within a single medium ${ }^{6 "}$.

Thanks to this flexibility in the modes of consumption, television programs have become a significant part of individuals' set of everyday experiences to the point that they now impact on the choices they make in conducting their lives, in looking for specific experiences, in defining and establishing their own social relations and identities.

Fan practices have become more and more relevant in the process of definition of both the consumption modes of TV shows and of the various ways in which individuals make sense of them.

The concept of 'fan' turns out to be quite problematic since it refers to a spectrum of definitions for different behaviors and levels of engagement. Furthermore, what constitutes proper fandom is an issue that fan theories have been trying to dissect and explain for a long time. The word 'fan' originates from the term 'fanatics' and, for quite a long time, it had a negative meaning. In 1992, in his book Textual Poachers, Henry Jenkins was able to demonstrate that the nature of fan involvement revealed an evident capacity for critical analysis ${ }^{7}$. More than a matter of passion for a media object or a practice simplistically ascribed to the category of the favorite hobbies, fandom reveals its relevance as a powerful tool in the building of identity and "in the positioning of one's self in the modern world ${ }^{8}$.

4 Henry Jenkins, Convergence Culture: Where Old and New Media Collide, op. cit., p. 95-96.

5 Carlos Alberto Scolari, Transmedia Storytelling: Implicit Consumers, Narrative Worlds, and Branding in Contemporary Media Production, International Journal of Communication, 3, 2009, p. 586-606.

6 Henry Jenkins, Convergence Culture: Where Old and New Media Collide, op. cit., 2006, p. 95.

7 Henry Jenkins, Textual Poachers. Television fans \& partecipatory culture, New York-London, Routledge, 1992. Jenkins' work and that of other scholars like Camille Bacon-Smith (Enterprising women: Television fandom and the creation of popular myth, Philadelphia, University of Pennsylvania Press, 1992) advanced a new perspective on fans and their passions and initiated a course of studies -the so-called 'first wave of fan studies'- that shed a new light on these consumers and their relevance to the discourses on media consumption.

8 Cornel Sandvoss, Fans: The mirror of consumption, Cambridge, Polity, 2005, p. 165. 
In this article, we will refer to the definitions provided by Mark Duffett: fandom as a term utilized to indicate "the social roles that [fans] inhabit"” and by Daniel Booth, according to whom the term also refers to a group of people "who work together, online and off-line, not only to interpret, create, and extend the mass media, but also to make the game itself. Mass media is not simply a game we play together; fandom itself, the name of that game, is a game we make together ${ }^{10}$ ". These characterizations support our argument regarding the construction of both subjectivity and intersubjectivity.

The changes that we have described so far have been inducing a mutation in the relationship between TV series and all those elements that constitute their context, such as the new broadcasting technologies, fan practices, the mutation of media markets. The aim of this paper is, therefore, to clarify how in the case of the TV series Game of Thrones, and with reference to Italy, the interlacement of textual and contextual elements can: a) determine different forms of experience in consuming media texts; b) contribute to the shaping of fans' subjectivity; c) give rise to distinct forms and levels of intersubjectivity as a result of the media practices individuals engage in.

In the next paragraphs, we will explore the phenomenology of this interlacement, trying to illuminate, to borrow Benjamin Black's words, "the swaying rope-bridge", a sort of link sometimes hard to perceive, but persistent, that exists between "that text and this context" -as a social psychologist would sayor "that context and this text" -as a media studies specialist would replay- in order to show the necessity to complement the two points of view to properly discuss a), b) and c).

In order to thoroughly present our analysis, and before focusing on the emerging practices of consumption that the above-mentioned transformations have determined, it is necessary to explain the meaning of the terms text and context on one hand, subjectivity and intersubjectivity on the other.

\section{Text and Context: Definitions}

To be clear from the beginning, we have to declare that the meaning of the term 'text' we will adopt in this paper comes from Eco's seminal work $A$ theory of Semiotics. Eco's definition of 'aesthetic text' -as we consider TV series- unfolds revealing two features of it that we regard as relevant to our analysis: "Finally, aesthetic texts possesses one quality that makes them a peculiar example of sign production labor intended to establish pragmatic relations between communi-

9 Mark Duffett, Understanding fandom: An introduction to the study of media fan culture, op. cit., p. 18.

10 Francesca Coppa, Digital Fandom: New Media Studies, by Paul Booth [book review], 2012, in Transformative Works and Cultures, no. 11 - http://journal.transformativeworks.org/index. $\mathrm{php} / \mathrm{twc} /$ article/view/450/338. 
cators, through a complex network of presuppositional acts. (...) To read an artistic product means at once: (i) to induce, that is to infer a general rule from individual cases; (ii) to abduce, that is to test both old and new codes by way of a hypothesis; (iii) to deduce, that is to check wether what has been grasped on one level can determine artistic events on another (...). Thus all the modes of inference are at work $k^{11}$.

A first important feature is determined by the fact that, according to Eco and Bonfantini ${ }^{12}$, who have developed Peirce's ideas, at least one of the three above-mentioned forms of reasoning -namely abduction- is rooted in the past experiences of individuals and points towards the experiences to come, by supporting them in the development of decision-making strategies that will therefore affect their actions. In the light of these considerations, we can state that the aesthetic text, by actuating perceptual/cognitive/logical actions, orientates its users to plan and realize action at an interactional level.

Let us consider now a second quote, this one also from Eco's $A$ theory of Semiotics: "(...) in the interpretive reading a dialect between fidelity and inventive freedom is established. On the one hand, the addressee seeks to draw excitement from the ambiguity of the message and to fill out an ambiguous text with suitable codes; on the other, he is induced by contextual relationships to see the message exactly as it was intended ${ }^{13}$ ". This quote underlines the basic role of the context in anchoring the interpretive process of the text to a third factor, that is distinct from the user and also from the text itself. Therefore, in using the term 'text' we will refer to an object that guides the interpretive work of its users along two directions. In short, it is as if the text says to its readers/viewers: "if you want to understand me, use all the reasoning tools at your disposal, especially those that -like abduction-are firmly rooted in the action. Be careful, never lose sight of the context! ${ }^{14 "}$

Let us now discuss the meaning of context. We will not take into account the meaning of the term 'context' proposed neither by 'first-generation semiotics ${ }^{15}$ nor by the textual theories, that is: those theories that are called 'secondgeneration semiotics ${ }^{16}$. We will base our analysis on the meaning of the term 'context' that is currently used in Pragmatics as initially defined by Levinson ${ }^{17}$. What is of interest in this definition is the indication of the five dimensions that

11 Umberto Eco, A Theory of Semiotics, Bloomington, Indiana UP, 1975, p. 275. Emphasis added.

12 Massimo A. Bonfantini, La semiosi e l'abduzione, Milano, Bompiani, 1987.

13 Umberto Eco, A Theory of Semiotics, op. cit., p. 276.

14 Umberto Eco, ibid., p. 277.

15 'Context': all the elements that form the setting of a term/text they go along with and by mean of which that term/text can be better understood and assessed.

16 'Context': the set of circumstances for the text enunciation, that is the psychological, historical and cultural factors that influence the production and the reception of a text.

17 Stephen C. Levinson, Pragmatics, Cambridge, Cambridge University Press, 1983, p. 22-24. 
can be related to the concept of context: a) the circumstantial dimension that refers to the time and space of the communication; b) the existential dimension, that is related to the ways individuals relate to reality as in, for instance, being able to express the difference between fiction and news; c) the institutional dimension, made of all the historical, political, cultural, ethical and social conditions that define the modes of production and reception of a text; $d$ ) the transtextual dimension, in which intertext, paratext and metatext add up together; e) the actional dimension, which comprises the set of the roles, the mental states, the competences and the actions of those who participate in the production process of the text. Except for the a), all the definitions mentioned above, in conjunction with the concepts of subjectivity and intersubjectivity, will be helpful to present and articulate the data analysis and discussion on which we will rely to present the relation between text and context.

\section{Subjectivity and Intersubjectivity: Two Useful Concepts to Describe Fan Practices}

Addressing the core issues, we intend subjectivity as a fluid and circumscribed image proposed by the subject to the social world, a portion of what the person is ${ }^{18}$. We consider it as a 'system of intentions', a sort of relational project based both on the Self and identity components selected by the subject and strategically used in the interaction on the basis of their relevance for the interlocutor(s).

Leaving aside Self's components, we need to clarify the role of identity in the construction of subjectivity.

Social Psychology considers personal identity as the result of a series of processes of interaction between subjects and determinants of social reality, considered as the expression of social contexts. But -and this is relevant to our analysis- such a concept can be barely considered as an 'observable'. If we observe interactions from a psychosocial point of view, we see behaviors conveying subjects' intentions that can be referred to the identity's repertoire. We do not see identities in action, but the action of some identity's component strategically selected by the subject, and this is precisely what we mean when we refer to the concept of 'subjectivity'. To say it in other words, subjectivity is the enactment of identity in the interaction. As a matter of fact, in order to be understood by their interlocutors during interactions, subjects shape their subjectivities according to feedbacks and artifacts offered by the context which is assumed in its relational, semiotic and material dimensions.

18 Carlo Galimberti, Francesca Cilento Ibarra, 'I' and 'Other' in online interactions: Intersubjectivity as a social bridge. Annual Review of Cybertherapy and Telemedicine, 2009: Advanced Technologies in the Behavioral, Social, and Neurosciences, 144, 13-152009, 2009, p. 13. 
In a more general way, we could say that subjectivities are 'entities' dialogically generated and continuously adjusted by social actors during their interactions. Therefore, any social interaction is featured by a unique combination of subjectivities created in a specific context at a given moment. This combination can be indeed considered the potential matrix of intersubjectivity. By means of this term -'intersubjectivity'- we refer to a specific frame of interaction which constitutes a shared world for the subjects to enact in ${ }^{19}$.

Rooted as it is in the subjectivities that generate it, intersubjectivity is the phenomenological bridge between the subject and the other(s). Intersubjectivity refers to the process that allows actors to create a shared world within which they can interact with a good level of inter-comprehension, that is of mutual intelligibility of their communicative intentions. Such a world is featured, at least, by four specific properties that consitute modalities of action and, at the same time, results of the actors' actions. The first characteristic of a shared world is the construction of the actors' subjectivities and their mutual recognition by actors themselves. The second one is the conjoint definition of rules regarding interaction management and the relationships between actors according to situations. The third feature is the definition of the objects involved in the interaction and, lastly, the fourth one derives from the combination of conversational and discursive rules that allows actors to talk about the objects. These four characteristics demonstrate that co-referring to a shared world is a signal of a back reference to the actors themselves ${ }^{20}$, that is: when actors talk about objects present within their world, they also give information about themselves, leaving clues, signs of subjectivity that are being elaborated during interaction ${ }^{21}$. The peculiarities of such world should be the conjoint definition of subjectivities and the rules to create and support relationships, as well as the definition of objects and the conversational rules employed to deal with them ${ }^{22}$. Examples of the usefulness of these four features in describing -from a psychosocial point of view- the construction of an intersubjective situation can be found in Galimberti \& al. ${ }^{23}$. Here the authors present and discuss three studies; we believe that a brief summary of the second one will give us the opportunity to

19 Carlo Galimberti, Segui il coniglio bianco. Strategie identitarie e costruzione della soggettività nelle interazioni mediate in Camillo Regalia and Elena Marta, eds., Identita in relazione. Le sfide odierne dell'essere adulto, Milano, McGraw Hill, p. 73-127, 2011, p. 114.

20 Francis Jacques, Dialogiques recherches logiques sur le dialogue, Paris, Presses Universitaires de France, 1979, p. 254-258.

21 Carlo Galimberti, Francesca Cilento Ibarra, 'I' and 'Other' in online interactions: Intersubjectivity as a social bridge, op. cit., p. 10-12.

22 Carlo Galimberti, Segui il coniglio bianco. Strategie identitarie e costruzione della soggettività nelle interazioni mediate, op. cit., p. 116.

23 Carlo Galimberti, Eleonora Brivio, Matteo Cantamesse, \& Francesca Cilento Ibarra, Intersubjectivity as a Possible Way to Inhabit Future Cyberplaces. Annual Review of Cybertherapy and Telemedicine: Advanced Technologies in the Behavioral, Social, and Neurosciences. 2010, 154, p. 9. 
better understand how the co-referring to shared objects and the back-referring to actors are processes consistent to one another and, at the same time, occur in the interaction. This study (Brivio, Cilento Ibarra, Galimberti, 2008) takes into account "twenty media fandom blogs linked to two different TV-shows communities (and analyzes them) in their structural and design elements in an ethnographic perspective to explore how people present themselves as member of a community ${ }^{24 "}$ " By means of this analysis, the authors showed that "while each blog stands alone and is basically independent from the other, bloggers all use the same channels of communication to foster feeling of connection to their community: both verbal and visual-iconic jargons refer to a world that is only meaningful to the initiated. The common language made of subtle references to the focus of the community is characterized by: content of different blog features (e.g. credits, faq, images) (...) iterated and repeated to stress the common interest (TV-show); interactions are actively encouraged but strictly regulated by spelled-out warnings all through the blog (e.g. 'friending' rules, credits for taking other people's fandom related artistic production) $)^{25}$ ". What follows is of particular relevance to support our stance: "Blogs are socially constructed places but are home to a specific person and therefore breaking the rules entails shunning from a specific blog and its fandom neighbors. Blogs are also places for individual expression and this is evident by the way bloggers use common content (in this case, a TV show) and recognized blog feature (e.g. header) to deliver a very personal self presentation as member of fandom. Through their Self Presentation, fans refer to the community thanks to use of common clues, but within these boundaries, they use their own or other's people skills to have original content which differentiate them from other fan $s^{26 "}$. In summary, this example entails that: activity ${ }_{1}$ ) each element of the blog refers to a community-specific jargon and conveys shared meanings; activity ${ }_{2}$ ) by manipulating shared elements of the blog structure, subjects say something about themselves as members of a specific fandom. In other words, we could say that this study is a good example of how subjects speak about themselves activity $_{1}=$ back-referring process) by means of shared objects' manipulation $\left(\right.$ activity $_{2}=$ co-referring process), interacting in contexts -fandom blogs- that can be considered as intersubjective asynchronous environments.

On the basis of our argumentation and of this example, we can conclude this paragraph by confirming that the concepts of subjectivity and intersubjectivity will be instrumental in describing the relationship between TV series and fan practices because they will allow us to point out specific psychosocial characteristics of the phenomena under investigation. 


\section{New Practices of Consumption and Interaction}

In order to illustrate the consequences that derive from the viewing processes of the texts (TV series) and the media practices that characterize the context of consumption, we will start by explaining the concept of media convergence as the main frame of reference for the changes that have been taking place in the current media landscape.

Convergence has become a crucial framework for understanding audience conduct and expectations since it represents more than just a technological change. In his seminal work, Convergence Culture, Henry Jenkins explains that convergence "represents a paradigm shift -a move from medium-specific content toward content that flows across multiple media channels ${ }^{27}$ ". This mobility of content destabilizes the idea of television as a discrete object: its programs have become available on a myriad of platforms and in a wide range of narrative forms. Audiences utilize a wide range of devices that allow them to take advantage of numerous venues through which to access the media content they are interested in, while also having the freedom to exert their power of choice in different spatial contexts, and at different times of the day. The practice of watching television has, therefore, gradually turned into a complex set of intertwined experiences that include a variety of roles for the participants, who find themselves absorbed in a continuous flow of media content and mediated encounters. To say it in Nico Carpentier's words: "there is now clearly an increased diversity of participatory practices supported by an increased availability of technologies ${ }^{28 "}$.

From the 1980s, television programs -TV series in particular- started to develop into "multi-, cross-, and transmedia projects ${ }^{29}$ " whose narrative structures extend beyond the boundaries of the traditional medium. Jason Mittell describes this structure as it follows: “(...) nearly every media property today offers some transmedia extensions, such as promotional websites, merchandise, or behind-the-scenes materials -these forms can be usefully categorized as para-texts in relation to the core text, whether a feature film, videogame, or television series ${ }^{30 "}$.

The notion of Jenkins' transmedia storytelling (2006) helps to explain the dynamics of consumers' immersion in fictional universes as a widespread strategy on the part of media companies, which is meant to create an alter-

27 Henry Jenkins, Convergence Culture: Where Old and New Media Collide, op. cit., 2006, p. 243.

28 Nico Carpentier, "New Configurations of the Audiences?", in The Handbook of Media Audiences, edited by Virginia Nightingale, Hoboken N.J., John Wiley \& Sons, 2011, p. 199.

29 John T. Caldwell, "Critical Industrial Practice Branding, Repurposing, and the Migratory Patterns of Industrial Texts", in Television \& New Media, 7(2), 2006, p. 99-134.

30 Jason Mittell, Complex TV: The Poetics of Contemporary Television Storytelling, New YorkLondon, NYU Press, 2015, p. 293. 
native reality that permeates the time and spaces of individuals' existences. By redefining the hierarchical links between the core text and its "peripheral extensions ${ }^{31}$ ", transmedia allows the creation of enlarged stories in which every element contributes to the definition of a new fictional experience, deeply immersive and varied in its multiple options. Media producers choose to conceive television stories according to this narrative technique because it helps to capture and retain audience attention: a) by offering a significant amount of content that consumers can interact with and/or consume in different fashions; b) by transforming imaginary worlds into expanded narrative brands. Brands represent "complex discourse universes with a strong narrative imprint ${ }^{32}$ ".

Game of Thrones represents a notable example of fictional stories that have been conceived according to the idea that fans of the shows are supposed to immerse themselves in their virtual realities: "the television industry has been providing more possibilities for viewer engagement to keep viewers' attention long after a program has aired ${ }^{33}$ ". Media texts in the guise of alternative worlds can be explored, but also re-arranged and improved, by audience members. This process of creative collaboration has been defined as a world-building experience $^{34}$, which is related to the employment of transmedia storytelling within the structure of the show. Fans are the privileged explorers of these imaginary universes since they "enter an emotionally significant relationship with mass-produced texts and commodities in which these come to function as extensions of the self [...] fans are themselves shaped through their object of fandom ${ }^{35}$ ". Furthermore, fans can be both attached to and critical of the media texts they choose to incorporate in their lives.

Moving from these premises on the concept of fans and on the ways they engage with specific media texts, we will answer the questions formulated in the introduction by making reference to the results of a study conducted with the Italian fans of Game of Thrones in 2015 in the city of Milan (Italy).

The exploration of Italian fans' practices and attitudes called attention to the mutual influences of the texts and context in a 'growing-in-complexity' consumption cycle, and to the dynamics that regulate the process of inter-

31 Jason Mittell, ibid., p. 294.

32 Carlos Alberto Scolari, Transmedia Storytelling: Implicit Consumers, Narrative Worlds, and Branding in Contemporary Media Production, op. cit., p. 599.

33 John T. Caldwell, "Critical Industrial Practice Branding, Repurposing, and the Migratory Patterns of Industrial Texts", in Television \& New Media, 7(2), 2006, p. 99-134.

34 For a more detailed description of the concept of world-building, we would recommend Marc J.P. Wolf, Building imaginary worlds: The theory and history of subcreation, New york-London, Routledge, 2014. At the following blog is possible to find an introduction, in the form of an interview betwwen Henry Jenkins and Mark J.P. Wolf, to the concepts of 'sub-creation' and 'primary' vs 'secondary' worlds: http://henryjenkins.org/2013/09/building-imaginary-worldsan-interview-with-mark-j-p-wolf-part-one.html.

35 Cornel Sandvoss, Fans: The mirror of consumption, op. cit., p. 164. 
subjectivity as the result of the re-definition of fan subjectivities, and of the mediated interactions that occur among fans.

\section{Methodology}

The methods employed for the data production were both quantitative and qualitative. The first phase of data gathering consisted in an online survey, which was implemented on the website SurveyMonkey.com and launched in late May 2015. In order to distribute the survey, we contacted many Italian websites dedicated to the show: the Game of Thrones Italian Facebook page; the movie and TV series reviews website Mediacritica; the Facebook page of Rai4, the national network channel that airs the series in Italy; the well-known website Cinefilos; and a popular site of Italian subtitles that allows viewers to watch the series' episodes online in English with subtitles. The managers of these sites expressed their interest in the research and agreed to post the links to the online survey. The questionnaire received a significant number of responses: 863 people in total participated from all over Italy. In terms of gender, $70 \%$ of the respondents were females and $30 \%$ males $^{36}$.

The survey provided initial insights into audience practices and it was instrumental to identify suitable participants for the qualitative phase of the study, that is, the focus group discussions. We ran two focus groups with fans of Game of Thrones in the month of June 2015 in Milan; each group consisted of 8 participants and lasted for about an hour and a half. During the moderation of the groups, we asked participants questions ranging from their viewing practices to activities related to the series (such as the production and/or distribution of both original and re-worked media content), as well as their opinions on the show's content (plot development and characters' profiles) and whether or not they considered themselves as fans of the TV show; the group dynamics allowed for interactions among the participants, who engaged in conversations on the proposed topics.

36 As for the reference age, $60 \%$ of the participants were between 20 and 29 years old, $20 \%$ between 30 and 39 years old, 10\% 19 years old and younger, the rest 40 years old and older. About $45 \%$ of the respondents belonged to the category 'high school student', while another $45 \%$ stated to have a university degree. 


\section{Findings and Data Analysis}

\section{The Multi-level Fictional World of Game of Thrones}

The attraction of Game of Thrones as a "complex textual network ${ }^{37 \text { " consists }}$ in its being "entertainment for the age of media convergence, integrating multiple texts to create a narrative so large that it cannot be contained within a single medium ${ }^{38}$ ". One of the main consequences of the employment of this narrative strategy for the creation of complex media products is represented by the several ways -via multiple technological devices- in which people can relate to these texts, that is: by appropriating them into their lives and/or even re-working them or parts of them, according to venues of consumption that are diverse.

Transmedia strorytelling is, in this regard and for our purpose of analysis, not only seen as a strategy employed by media companies and as a means for consumers to actively participate in the circuit of media production/distribution; it becomes relevant in presenting case studies that allow to investigate more in depth the complexity of the dynamics between text and context.

In particular, we will refer to a media landscape in which the neat separation between these two entities has been gradually eroded by:

a) the 'infiltrations' of the text in the context in the form of TV series presented as enhanced narratives with media extensions;

b) the blurring of traditional roles, exemplified by consumers who have now the chance of becoming 'producers' of new texts generated in the context of consumption.

Game of Thrones is a meaningful example of the above-mentioned transformations: an enhanced fictional world with media extensions that constitute multiple consumption paths for audiences to explore and experience. The show is considered a vigorous illustration of a cutting-edge, multilayered narration; it is highly realistic and engaging, with supernatural elements to embellish the plot and impressive production values.

The basic idea that underlies the serialized narrative of Game of Thrones is that of the game: characters are continually involved in dangerous confrontations and strategic fights for the conquest of power. The series' transmedia framework has been conceived accordingly: the main features and apps available online and on mobile devices are structured as interactive games for the purpose of involving audiences in a system of competitions that reinforces the brand image of the product. Some examples of these games are:

37 Carlos Alberto Scolari, Transmedia Storytelling: Implicit Consumers, Narrative Worlds, and Branding in Contemporary Media Production, op. cit., p. 601.

38 Henry Jenkins, Convergence Culture: Where Old and New Media Collide, op. cit., p. 95. 
Game of Thrones Join The Realm, Game of Thrones Pinterest Profile, The Italian game FantaGot, Game of Thrones Ascent. Game of Thrones' applications for smartphones are numerous: i.e., "Game of Thrones Wiki", "Game of Thrones Trivia With Friends", "News For GoT", "IQuiz For Game of Thrones", and keep viewers updated on 'what-is-new' about the production of the TV show, allowing individuals to engage in games with friends and to test their own knowledge of the universe created by George R.R. Martin.

In addressing their audiences beyond the official programming schedule, producers have been trying to sell them tastes of the atmosphere that defines the tumultuous universe of Game of Thrones.

While the distinction between traditional roles (old producers $v$ active consumers) is progressively blurring and the 'growing-in-complexity' structure of texts like TV series has been affecting the modes of consumption, the definition of both text and context is still a matter of analysis in this field. Cornel Sandvoss called attention to the fact that, in the current media environment "the construction of textual boundaries has shifted from producers to media consumers ${ }^{39 "}$. This progressive change in the relationship between producers and consumers has also been affecting the relationship between text and context. We will explore this relationship with reference to the dynamics of text/context reciprocal influences, in order to provide adequate answers to the questions that these issues bring with them. We will accomplish this task by adopting a double perspective, articulating the contributions of two disciplines: Media Studies and Social Psychology of Communication. In the previous paragraphs, we referred to concepts that derive from these two fields: new practices of consumption on one hand, subjectivity and intersubjectivity on the other. We will use these concepts to explore 'what is happening' on the edge between aesthetic texts (like TV series) and context (in which fans' practices take place) with reference to the subjects who consume these texts and inhabit this context.

\section{The Viewing Process and the Influence of the Text}

The main practices that exemplify the influence of the texts on fans' activities inside the context of consumption are: a) the choice of the viewing platforms (television medium and laptop), b) the attitude of spectators toward the viewing process, c) the choice of the language and d) the tendency to watch more episodes in a row ('binge-watching' habit).

Italian fans choose the traditional medium of television as their first option to watch the series' episodes; second for this purpose is the laptop. The viewing activity is, in the first place, a moment of relaxation and a form of entertainment: the combination 'television/laptop' represent the best way to fully enjoy

39 Cornel Sandvoss, "Reception", in The Handbook of Media Audiences, op. cit., 2011, p. 246. 
the high quality production of Game of Thrones. For this reason, technological devices like smartphones and iPhones are more willingly employed to watch short clips and trailers, but not the original core content -that is, the full episodes- that deserves fans' full attention and a high-definition technology:

- The series makes a great viewing on the television screen... You enjoy it much more.

- I stream the episodes, and I usually watch them by myself on the computer.

- No, on the mobile definitely no, it is too small!

- Game of Thrones looks like a movie, it is a series that has to be seen in a specific context that allows to get the best out of its viewing!

The viewing process is, therefore, described as a focused activity by essentially the totality of fans of the show. The series is very complex in terms of the development of the plot, the convoluted dialogues and the characters' connections, therefore it is essential to pay a full attention while the episodes are running.

The majority of the Italian fans stated that they desire to watch the series' episodes in original language with Italian subtitles. This is also a modality of 'staying active', even if this requires a higher level of attention during the viewing. In giving up the linguistic automatism and choosing the original version of the show, fans seem to be pursuing a strategy that allows them to appropriate the cultural dimension of the text. Indeed, fans are quite resentful of the dubbed version of the series since it appears to not be faithful to the original content:

- In the dubbed version they [the Italian distributors] cut or modify some parts, and usually not in a proper way.

- We watch the episodes in original language on SKY Atlantic.

- The problem with the dubbed version is that the Italian voices change the characters.

The narrative of Game of Thrones, so full of twists and cliffhangers that 'hook' viewers and incite them to keep watching in order to discover what is going to happen, encourages an uninterrupted viewing process: in this regard, the practice of binge-watching is directly related to, and affected by, the form in which the text is released (single episodes of about one hour each) and its internal narrative structure (the plot of the whole text develops according to continuous narrative lines that link the various episodes together).

Binge-watching exemplifies the influence of the text on the modality of viewing, but it is also instrumental in supporting activities that involve fans' interaction (i.e.: active participation in multiple discussions on the series).

As a form of time management and participation in communicative exchanges on the series, the practice of binge-watching allows us to move our attention from the influence of the text to what viewers do in the actual context of consumption. From this point of view, binge-watching represents an activity that regulates both the dynamics of the influence of the series and fans' behaviors, therefore exerting a function of connection between text and context. 


\section{Inside the Context of Consumption: Fan Practices between Engagement and Construction Activities}

Beyond the viewing process of the original text as a practice strictly dependent on the act of enunciation, fans have today the chance to manage their own viewing schedules and perform a variety of new and significant activities: the search for extra material/information on the series and the cast, discussions about the plot and the characters, the reading of blogs and books about the story, the purchase of merchandise, the downloading of applications, the recreation/reworking of parts of the fictional world as the result of fans' creativity (cosplay, fan art works, fan fiction, etc.). The analysis of these activities is of relevance from a double perspective: in the first place, it identifies the intent of the official producers to create and offer media content that is meant to be consumed by people in a context of consumption that transcends the mere viewing process of the TV show. Second, it provides useful insights on fans' roles as explorers of these imaginary universes.

With reference to the interesting aspect that came out is the fact that, in the context of consumption, fans engage with this text by investigating, analyzing and speculating on the stories they tell, as well as on the characters they depict, according to personal pathways that do not follow those created by the official producers of the TV program. The study exposed the importance of Wikipedia and YouTube as useful sources of extra information for fans, as well as the official Facebook pages of Game of Thrones; other social media like Twitter, Instagram and Tumblr are also taken into account for the variety of comments and opinions they provide:

- I do share comments with people I don't know on Twitter.

- I do participate in the online discussions -on the Facebook page of Game of Thrones and on the Instagram page as well.

- No, I have never visited the official website... I prefer the online interaction with other fans.

This type of activity that refers to the interaction among fans contributes to the construction of their intersubjectivity. Media texts like Game of Thrones do not stand only as visual narratives to be watched on a variety of screens; beyond the boundaries of those visual frames, they turn into topics of discussions (face-to-face and online conversations), means of communication (books, blogs, forum discussions, articles and reviews), means of social interaction (games, cosplay performances, shared viewing of the episodes, production and distribution of fan-made content):

- The cosplay is becoming more popular in Italy at the moment.

From this standpoint, the context of consumption becomes, at the same time, a field of negotiation and a privileged ground for the process of appropriation of media texts. Our focus here is on the latter point; Italian fans of Game of Thrones clearly stated their desire to share thoughts and opinions about the series with close friends and other fans: 
- My sister, some friends and I have created a WhatsApp group and we use it to share comments on the episodes.

- To discuss about it with friends is the most important thing.

- I usually watch the episodes by myself on the computer and then I comment with my friends the following day.

The appropriation process takes place in the context of consumption according to the perspective of reflexivity, that consists in the adoption of a critical approach to the narratives; and to logics of interaction that refer to the system of live conversations with friends and relatives, online communicative exchanges with other fans, research of fan-made material. Reflexivity is dependent on the comprehension of the series as a media text. In answering the question "Why do you like the TV series?", fans clearly expressed their sense of closeness and identification with the stories and the characters, despite the fact that Game of Thrones' events take place in a sort of Middle Age era, very distant from our current times:

- The series knows how to touch your emotions... You find this whole new world in front of you and you feel like you are in it... Even the characters make you think: what would I do if I were in the same situation?... It is really engaging and fascinating... No other series is like Game of Thrones at the moment!

- Game of Thrones creates this strong empathy with the characters... It is not like any other TV series and I do watch many... But with Game of Thrones you develop a real feeling of affection for the single character... Helshe becomes one of us.

Beyond the series' time frame and the rules that pertain to the specific genre, the concept of realism becomes, for the Italian fans, the key term through which that feeling of closeness is explained; the show is capable of depicting the complexity of the human soul in such an effective way that the main characters become, with their set of qualities and vices, mirror images of the human being:

- The characters in Game of Thrones are interesting because they are complex, even from a psychological point of view... There are many that I like!

- In my opinion, the characters symbolize all the different human traits! At least once in our lives, each of us has been Cersei or Arya or Ser Davoss!

The preference that fans revealed for the use of social media and their interest in cosplay performances constitute two clear examples of the building process of the context, conceived as a network of communicative exchanges. In particular, we do believe that these practices are noteworthy instances of two specific components of the context, those that refer to the points e) and d): completion of trans-texts; communicative acts in which roles, mental states and competences of individuals are intertwined and, as a result, generate discursive works and/or digital artifacts related to the TV series. 


\section{Conclusions}

Let us go back to the relationship between text and context to focus on the possible link between them: can it be described as a 'swaying rope-bridge' or as something different, more solid and articulated?

An element that has come to our attention is represented by the importance of action among Italian fans. The findings from the focus groups have confirmed what literature states in this regard ${ }^{40}$. In our opinion, what exceeds the already known categories is the intensity of this activity and the forms that it assumes with regards to Game of Thrones. As we have reported, this flux of activity develops in both directions that go from the text to the context and vice versa.

With reference to the first direction -presented in the paragraph 'The Viewing Process and the Influence of the Text'- we identified two important dynamics:

a) Italian fans' interpretive work is dependent on fundamental choices regarding technological devices (multiple platforms), cultural elements (original language vs Italian language), personal tastes (binge-watching), practical and organizational aspects (the time of the viewing), relational connections (with whom they watch/discuss about the TV series). These choices can be considered actual 'modulators' of fans' action since they impact on the realization of consumption behaviors, of the attribution of meaning and of the sharing of textual contents.

b) on the basis of these choices, Italian fans build their own subjectivity. They decide according to them which elements, arising from the interpretive work of the text, are worth becoming part of their identity repertoire and, in particular, which elements will be brought in the system of interactions.

Therefore, a) and b) points allow us to state the active role played by fans in the interpretive process but also to point out that their actions go beyond this same process since they lay the foundation to act in/on the context.

With reference to the second direction -presented in the paragraph 'Inside the Context of Consumption: Fan Practices between Engagement and Construction Activities'- we observed the presence of activities that reveal both illocutionary engagement (the regular attendance of social networks), and social commitment (occasional participation in the cosplay phenomenon). These activities give fans the opportunity to express their subjectivity by interacting with each other, with the final aim to build intersubjective situa-

40 See Henry Jenkins, Convergence Culture: Where Old and New Media Collide, op. cit., and Carlos Alberto Scolari, Transmedia Storytelling: Implicit Consumers, Narrative Worlds, and Branding in Contemporary Media Production, op. cit. 
tions. This happens through the construction of artifacts that are both digital (exchanged, for instance, within the social networks) and material (cosplay costumes). In both cases, the co-constructing and exchanging processes constitute experiences that are more engaging than the mere belonging to a fan community. As we came to note, often these artifacts can return to the original texts through a process of assimilation in their textual universes, or also by fostering the shared consumption of the TV series.

As we have stated, the concise description of the relationship between text and context is repeatedly intersected by the concepts of subjectivity and intersubjectivity. If subjectivity is the enactment of identity in the interaction, this means that the making of fans' identity is not only based on projective and introjective identifications, but it is also the result of a building process, strategically conducted, of an identity repertoire strictly related to the consumption and interpretive experiences of the TV series. In other words, it is possible to consider fans' subjectivity as a structured set of perceptions, representations, attitudes, habits, values etc., instrumental in expressing fans' relationship with the TV series. Beyond the anthropological interest for this kind of analysis, to acquire knowledge of fans' experience in terms of subjectivity can be relevant for commercial companies whose final purpose is to attain a clearer profile of their target audiences so as to tactically advertise their services and products to them.

The reference to the concept of intersubjectivity and to its manifestations within the discourses generated by participants during the focus groups, allows us to add an element of psychosocial nature to the concept of fandom, and to see it not only as a 'subculture' of a community of fans.

Let us end with a question and four subject-to-confirmation answers: what does intersubjectivity add to the sense of (belonging to) a community? In our opinion, there are at least four elements that are to be taken into account to answer this inquiry and that pertain to an intersubjective situation:

1) fans' possibility of 'deciphering' the text by referring to their experiences, to their own subjectivity and/or group of reference;

2) fans' possibility to perform strategically, carrying out actions that go beyond the mere reception of the texts and/or their reproduction;

3) the fact that 1) and 2) can take place within a universe made of characters, plots, fictional worlds, partly suggested by the series and partly 'co-constructed' by fans themselves;

4) fans' possibility to intervene on the rules of their interaction when they deal with elements that constitute the above-mentioned universe.

Cosplay performances and fan-made content represent two examples in which all these four elements add up together in a significant way. For this reason, cosplay performances and fan-made content can be classified, respectively, as intersubjective experiences and intersubjective artifacts. They are 
like shuttles travelling from transtextuality to intersubjectivity, 'via' all those occasions linked to the production and consumption of content and social situations.

In the light of these considerations, we can state that the interlacement between text and context that we have described is more than a mere hypothesis. Next studies will possibly tell us if the identified link between TV series -considered as aesthetic texts- and new practices of consumption, the employment of trans-media storytelling, user generated contents and fan behaviours -considered as contexts for these texts- is more solid and articulated than Black's "swaying rope-bridge". And, even more important to us, finally discover that in this domain, text(s) cannot even exist without contex$\mathrm{t}(\mathrm{s})$ and vice versa.

\title{
Carlo Galimberti \\ Carmen Spanò
}

Centro Studi e Ricerche di Psicologia della Comunicazione Università Cattolica del Sacro Cuore, Milano carlo.galimberti@unicatt.it carmenspano78@gmail.com

\begin{abstract}
Television has been changing for a number of years due to the growing proliferation of platforms and the interconnection of multiple media forms. These changes have reshaped the relation between the idea of text(s) (i.e., TV series) and context(s) (i.e., fan practices) in the process of media consumption. This paper aims to clarify how, in the case of the TV series Game of Thrones (HBO) and with reference to an empirical research carried out by the authors, the interlacement of textual and contextual elements can determine different forms of experience and different levels of intersubjectivity in fans' practices.
\end{abstract}

\section{Keywords}

Intersubjectivity, Fan Practices, Media Consumption, TV Series, Game of Thrones.

\section{Résumé}

Depuis un certain nombre d'années, la télévision a été modifiée par la prolifération croissante des plates-formes et de l'interconnection de multiples formes de médias. Par rapport au processus de consommation des medias, ces changements ont remodelé la relation entre les concepts de texte/s (i.e., séries télévisées) et de contexte/s (i.e., les pratiques des fans). Cet article vise à clarifier comment, dans le cas de la série télévisé Game of Thrones et en référence à une recherche empirique menée par les auteurs, l'entrelacement des éléments textuels et contextuels peut determiner différentes formes d'expérience et différents niveaux d'intersubjectivité dans les pratiques des fans.

\section{Mots-clés}

Intersubjectivité, pratiques des fans, consommation des médias, séries télévisées, Game of Thrones. 